\title{
LA SOCIOLOGIZACIÓN DEL PENSAMIENTO JURÍDICO ${ }^{1}$ The Sociologization of Legal Thought
}

Ingrid Regina Petro González ${ }^{2}$

Fecha de recepción: 25 de febrero de 2015

Fecha de aceptación: 12 de mayo de 2015

SUMARIO: 1. Introducción; 2. Un acercamiento a la postura teórica defendida; 3. Fundamento teórico; 4. La imbricación sociología jurídica-teoría del derecho; 5. La sociologización del derecho; 6. A manera de colofón; 7. Conclusiones; 8. Bibliografía.

\footnotetext{
${ }^{1}$ El presente artículo surge de un proyecto desarrollado en la Universidad Libre de Pereira y en su desarrollo la autora actuó como investigadora principal.

2 Abogada, Doctoranda en Derecho, Magister en Derecho Procesal, Especialista en Derecho Administrativo y Derecho Procesal Contemporáneo, Docente Investigadora de la Universidad Libre seccional Pereira, Email: irpetro@unilibrepereira.edu.co
} 


\section{COMO SE CITA ESTE ARTÍCULO (APA 6)}

Petro González, Ingrid Regina (2015). La Sociologización del Pensamiento Jurídico. Revista Jurídica Mario Alario D'Filippo, VII (14), pág 85-94.

\section{RESUMEN}

El presente artículo propone un acercamiento a la problematización de la concepción del derecho como campo del ejercicio del poder, connotante de una ideologización del positivismo jurídico, para el ejercicio de una acción comunicativa instrumental, que al perder de vista los criterios habermasianos de la acción comunicativa moral, funge como autoritarismo de la élite con el poder de producir las normas.

\section{PALABRAS CLAVE}

Sociología del derecho, sociologización, teoría de la acción comunicativa.

\section{ABSTRACT}

The present article proposes an approach to the problematization of the conception of law as a field of the exercise of power, connoting an ideologization of legal positivism, for the exercise of an instrumental communicative action, that losing sight of the Habermasian criteria of communicative action Moral, functions as authoritarianism of the elite with the power to produce norms.

\section{KEYWORDS}

Sociology of law, sociologization, theory of communicative action. 


\section{INTRODUCCIÓN}

Este artículo cientifico responde a la formulación del problema de investigación ¿Cuál es el alcance del control social a la producción normativa para la garantía de los derechos fundamentales? El objetivo general del mismo consiste en establecer el alcance del ejercicio del control social a la producción normativa jurídica por parte del estado teniendo como referente la garantía a los derechos fundamentales.

El enfoque metodológico es sociojurídico con análisis cualitativos de la acción comunicativa que despliegan los ciudadanos integrantes de la diversidad de colectivos sociales en relación con la ponderación de la eficacia social de las normas producidas legalmente por la institución reconocida socialmente como legítima para la producción de la normativa reguladora de la acción del Estado para garantizar los derechos fundamentales.

\section{UN ACERCAMIENTO A LA POSTURA TÉORICA DEFENDIDA}

La pregunta se justifica por cuanto responde a la necesidad de abocar el control de constitucionalidad a la producción normativa desde el ejercicio del control social encaminado a legitimar la producción legal de normas desde la garantía a la perspectiva de derechos con enfoque poblacional.

Es una perspectiva relevante, pertinente y actual por cuanto proyecta el ejercicio del control social, a través de la acción comunicativa del principio del discurso, a deliberar si el contenido sustancial de las normas producidas legalmente (siguiendo el procedimiento formal instituido para la producción de normas) efectivamente se orienta a garantizar los derechos fundamentales.

\section{FUNDAMENTO TEÓRICO}

"La filosofía del derecho, al decir de Robert Alexy, se ocupa de lo que es el derecho, de lo que debe ser el derecho y de cómo acontece lo que es y lo que debe ser el derecho" (La naturaleza del derecho. 2005).

Se trata de una reflexión que va en busca de la verdad. De ahí que el término "Filósofo" designe "amor a la sabiduría"; actitud de búsqueda demandante de criterios metodológicos que permitan trascender el limitado contorno de la erudición metafísica, encaminando una acción comunicativa "que delibere y describa aséptica y fríamente la realidad, alejado de ella, sino que se involucra en la pasión del saber" (FALCON, 2004).

La caracterización de la filosofía del derecho expuesta por Alexy como la disciplina que se encarga de estudiar "lo que es el Derecho", lo que debe ser el derecho y el cómo acontece lo que es y lo que debe ser el derecho, pondera la relación jurídico material del derecho en relación con la validez o legalidad de la producción de las normas jurídicas. 
Reflexión del filosofar el derecho que se enmarca, tal como lo señala Habermas, en el contexto "de un discurso práctico orientado a comprobar si una norma cumple las condiciones de validez más allá del principio de legalidad haciéndolo extensivo al principio moral. Una norma es moralmente valida si cumple con los criterios de la racionalidad comunicativa". (2009).

Significa lo anterior que una norma debe destinarse a posibilitar la garantía de los derechos fundamentales, condición objetivo de la finalidad constitucional de la vida en condiciones de dignidad, antes de su expedición o promulgación, para evitar atropellos a los habitantes del territorio.

En palabras de Habermas, si el ciudadano es destinatario de las normas tiene derecho a ser co-autor de las mismas. Como no todos podemos ir al Congreso a producir normas, las que son producidas legalmente en esta institución tienen derecho a co-legislar, haciendo uso de la razón jurídica, deliberando si las normas producidas legalmente, en efecto, son eficaces socialmente.

El lenguaje es uno de los potenciales esenciales del ser humano tal como lo señala Habermas, desde este punto de vista esta racionalidad comunicativa puede conectarse con la legalidad y es aquí donde incorporamos la validez de las normas jurídicas; como la eficacia de las mismas deben ir concatenadas para evitar violaciones a los derechos humanos, una norma puede ser legal pero no es legítima, en cuanto esté violando los derechos fundamentales establecidos en la Constitución Política.

Como en el contexto colombiano el control constitucional se ejerce con los criterios del Estado liberal de derecho, eludiendo hacer extensivo el control de legalidad (derecho procedimental) al control del contenido sustancial de la norma, se debe apelar al control social, a través del uso de la razón jurídica materializada en el principio del discurso.

Una de las disciplinas jurídicas es la teoría general del derecho la cual investiga la estructura de las normas, su clasificación, sus relaciones, las figuras jurídicas básicas, la producción, destrucción e interpretación de las mismas. (CORREAS, 2002).

La ley proviene de la ideología y no de relaciones sociales, aunque sea luego a las relaciones sociales a quienes haya de recurrir para explicar la presencia de tal ideología en la conciencia del legislador.

La teoría general del derecho, cual ha sido creada principalmente por el positivismo que reconoce a Kelsen como la figura inspiradora de tal teoría.

El objeto de la sociología jurídica es la jurisprudencia normativa y cuya finalidad es describir las normas descritas y el trabajo de la sociología seria interpretar o explicar por qué se permiten esas normas en un territorio. 
Silva (2009, p. 72) citando a Luhmann observa que el objeto de la sociología debe hacerse extensivo "al estudio de la estructura del derecho, y considerar dentro de su esquema teórico los actores sociales, para dar paso a los sistemas de acción comunicación", desde los cuales legitimar políticamente la validez jurídica de las normas a partir de su eficacia social.

La legitimidad, validez y eficacia son ponderadas por Luhmann, como criterios de valoración jurídica de la producción normativa. Situación relievada por Habermas cuando incorpora el principio del discurso como acción comunicativa de los destinatarios de las normas, a través del cual se constituyen en coautores de las mismas, al legitimar o deslegitimar políticamente la normas producidas válidamente por la institución destinada por la sociedad para el ejercicio de la función reguladora de la condición relacional de los colectivos humanos localizados en los distintos territorios.

Cuando Habermas se pregunta "quién nos garantiza a nosotros que las personas que nosotros elegimos para que nos representen en la institución que produce las normas, las normas producidas por ello representen en efecto los intereses públicos" (Facticidad y Validez, 2005), él mismo responde que nadie. Por eso incorpora el principio del discurso como factor de control social a la producción normativa en perspectiva a su función social de servir de instrumento al garantismo de los derechos fundamentales de todos los destinatarios de las normas.

En efecto, la universalización de la razón jurídica, como práctica social e institucional de sociedades civilistas, está mediada por la apropiación social de la comprensión de la función social del derecho cómo técnica de producción y aplicación de normas legales, que contribuyan a garantizar la vida en condiciones de dignidad. La superación de la tercera fuente del sufrimiento humano, precisada por Freud, como la debilidad de las sociedades en la implementación de técnicas de producción de normas, remite a considerar aquella concepción del derecho como campo del ejercicio del poder productor de normas reguladoras del favorecimiento del interés particular (de clase, grupo, partido o facción política) en nombre del interés público.

El proyecto de investigación que originó este trabajo, propone un acercamiento a la problematización de la concepción del derecho como campo del ejercicio del poder, connotante de una ideologización del positivismo jurídico, para el ejercicio de una acción comunicativa instrumental, que al perder de vista los criterios habermasianos de la acción comunicativa moral, funge como autoritarismo de la élite con el poder de producir las normas.

La intencionalidad es concitar la atención en torno al problema del derecho procedimental, mediado por la capacidad de los autores y actores de las prácticas jurídicas de advertir la corrediza frontera entre el interés particular y el público, que no es otra que el deslinde 
entre la ideologización del derecho, que subyace al formalismo jurídico, presentado en forma de "Teoría pura del derecho" (Kelsen y Hart) y una teoría procedimental del derecho, con fundamento en los criterios éticos de una acción comunicativa transparente.

En el primer caso se está ante la postura ideológica de la élite dominante de las mayorías que formalizan el derecho para proteger sus particulares intereses en nombre del interés público, en el segundo caso, se está ante unos criterios aceptados por todos los hablantes, universales que se proponen la construcción de acuerdos procedimentales que reconozcan o tengan en cuenta la maximización de la eficacia social de las normas válidas jurídicamente.

En suma, se propone relievar la necesidad de la sociología jurídica como disciplina fundante del derecho, necesidad reconocida incluso por Kelsen (2a. Edición,1960), paladín de la teoría pura del derecho quien "concibe la validez como una propiedad o atributo esencial de cualquier norma, propiedad que a su vez se identifica con su fuerza obligatoria"(LOPEZ, 2004, p.1).

\section{LA IMBRICACIÓN SOCIOLOGÍA JURÍDICA-TEORÍA DEL DERECHO}

El paralelismo temático y conceptual de la dogmática jurídica y la sociología del derecho se reconoce desde la comprensión de la función social del derecho. Las ciencias jurídicas, como región específica del campo de la ciencias sociales, que se ocupa de la fenomenología de la regulación de las relaciones convivenciales a través de normas, pondera como fuente primaria la necesidad contingente de la regulación heterónoma desde la incapacidad de la regulación autónoma de la vivencia con el otro, en atención a la naturaleza humana signada por el primado biológico de la condición emocional y del egocentrismo propio de la condición humana.

El derecho tiene la función social de contribuir a la humanización del animal biológico humano. Perspectiva que destaca la necesidad de conocerlo, para saber cómo regular su condición relacional con enfoque universalista. Este plano pone de presente la percepción freudiana de la precariedad societal en relación con las técnicas de producción y aplicación de normas, identificadas por el pensador "del malestar en la cultura" como la tercera fuente del sufrimiento humano.

Es evidente que la sociología del derecho emerge como una disciplina fuente de la teoría del derecho, sin pretensiones de sustituirla. Busca, en consecuencia problematizar la formalización del derecho (positivación) y su institucionalización, a partir de las puestas en práctica de las decisiones jurídicas.

Este plano de acción práctica amplía el objeto del derecho, circunscrito por la prevalencia del positivismo jurídico al limitado contorno de la norma, esto es, a su validez jurídica, 
haciéndolo extensivo a su legitimación, a partir de su eficacia social, en relación con la finalidad moral de la vida en condiciones de dignidad.

La norma per se encubre la realidad de que más allá de su mismidad, ésta responde al interés de un sujeto autor que vive las contingencias de sus destinatarios, es decir, que tiene intereses distintos al interés del derecho como disciplina científica puesta al servicio de la dignificación de la vida.

No se trata de la sustitución de la tradición jurisprudencial ni de la dogmática jurídica como objetos del derecho, sino de la consideración de su validez a la luz, tanto frente al formalismo procedimental como respecto a los fines entrañados en la relación derechomoral.

En efecto, la evolución misma del derecho no depende del derecho en sí mismo sino de la dinámica social en perspectiva a la dignificación de la vida. De este modo, el derecho como tal, esto es, como ciencia social, se traduce en política de vida. De ahí el factum de la relación derecho moral, puesto que la vida es un valor moral, al que se ponen en servicio las ciencias en general y dentro de ellas las ciencias sociales, en particular el derecho, que asume como objeto la regulación de la vida en condiciones de dignidad, de manera positivada.

\section{LA SOCIOLOGIZACIÓN DEL DERECHO}

En sentido estricto la sociologización del derecho versa sobre un desarrollo normativo en sentido realista. Este se conecta a un proceso de institucionalización, que como ya se advierte se hace irreductible al formalismo jurídico propio del positivismo de la jurisprudencia de conceptos y de la tradición kelseniano hartiana.

La sociología del derecho se sitúa más allá del iuspositivismo y del iusnaturalismo, a fin de conjugar normativismo con realismo, o si se prefiere, de relacionar del normativismo en el plano teórico jurídico con el neoempirismo en el plano de la sociología general; que conduce a reconocer que las normas no son realidades ontológicamente diferentes de la realidad de los hechos empíricos, una vez que se ha definido como "real todo aquello que tiene existencia en el tiempo".

La crisis del positivismo, es decir, de una teoría formal del derecho, que estudia el derecho en su estructura normativa, independiente de los valores a los que sirve esta estructura y del contenido que ella encierra, encuentra su apoyo en la teorización de los científicos sociales de finales del siglo XIX, quienes sostuvieron el carácter pragmáticamente avalorativo del positivismo jurídico y la imposibilidad estructural de identificar criterios de juicio de orden moral para decidir en derecho y en política, aduciendo la imposibilidad de un conocimiento objetivo de los mismos. 
El debate sociológico contemporáneo ha puesto en crisis los dos presupuestos sobre los cuales reposaba el positivismo jurídico, determinando la apertura de la filosofía del derecho, tanto hacia el mundo de los valores ético-políticos como hacia el mundo de los hechos.

La premisa de la teoría sociológica contemporánea está constituida por el reconocimiento de la inadecuación del iuspositivismo, que se vale de nociones "ideales" situadas por fuera del mundo de la vida, perdiendo de vista que el derecho se encuentra profundamente calado en la realidad.

El derecho se sitúa en el plano de los hechos institucionales, que tienen su origen en reglas constitutivas en función de fines particularmente relevantes para la sociedad, como la protección de la vida y de la seguridad de los asociados y la distribución de los bienes, inevitablemente insuficientes para satisfacer por completo las demandas de cada asociado.

Este plano situacional interpela la interdisciplinariedad en el campo de las ciencias sociales, de manera particular, la sociología, y de las ciencias humanas, entre ellas, la filosofía, para hacer relevante que los ordenamientos jurídicos no pueden ser reducidos a meras estructuras normativas y que al lado de las normas existen los principios de acción práctica, que van más allá del derecho, en cuanto se refieren a objetivos (como el bienestar de la comunidad) o valores (entre los cuales los derechos individuales). Los cuales representan un estándar que debe ser observado no porque provoque o mantenga una situación (económica, política o social) deseada, sino en cuanto es una exigencia de justicia o de corrección, o de alguna otra dimensión moral.

\section{A MANERA DE COLOFÓN}

La sociología del derecho constituye la disciplina complementaria de los ordenamientos jurídicos. En efecto, las normas jurídicas son válidas en cuanto establecidas y pueden ser modificadas tan solo mediante una deliberación, mientras que los principios de acción práctica del derecho son válidos en cuanto corresponden a exigencias morales sentidas en un determinado momento. Los jueces deben recurrir a los principios para fundamentar las decisiones jurídicas, puesto que sin apelar a ellos, es decir, asumiéndose como "juez boca de la ley", no sería posible aplicar una norma sin cometer con ello una injusticia.

De igual manera, el legislador debe someterse a criterios de valoración moral en la producción normativa, pero no al relativismo moral societal sino a los valores y principios de acción práctica constitucionalizados. Entre ellos la endoxa de la vida en condiciones de dignidad que se objetiva en una regulación normativa garante de los derechos fundamentales. Pero como para el destinatario de la norma nadie puede garantizar que esto ocurra en efecto, a éste solo le queda como recurso el principio del discurso, la acción 
comunicativa que delibera la legitimidad política de la validez jurídica de las normas con fundamento en su eficacia social, que no es otra que la garantía de los derechos fundamentales.

Sobre todo en nuestras condiciones de crisis institucional de los organismos de control constitucional, político, administrativo, fiscal, jurisdiccional; sesgados respectivamente en el control formal y no sustancial de la producción normativa (Caso Ley 100 de seguridad social integral), en la negociación de prebendas más que en la producción normativa en derecho, que en el control administrativo y fiscal, y que en el control a las decisiones judiciales en derecho. Sólo queda el recurso del control social, a través del uso del principio de discurso, acción comunicativa deliberadora de las condiciones de eficacia social de las normas producidas legalmente (validez jurídica).

\section{CONCLUSIONES}

Aunque no se puede desconocer que la democracia constitucional colombiana tiene avances significativos, lo cierto es que hay que profundizar el proceso de institucionalización del ejercicio del control institucional para posibilitar la balanza de los pesos y contrapesos.

Dado que el control institucional de constitucionalidad, político, administrativo, fiscal y de protección de los derechos humanos se encuentra debilitado por haberse distorsionado la relación gobierno oposición en la administración pública y en el ejercicio del poder político, en el entretanto de su necesaria y sana reedición, es menester fortalecer el alcance del uso de la razón jurídica para el ejercicio del control social a la acción pública del Estado, de manera especial y preponderante a la producción legislativa.

El uso de la razón jurídica interpela al sistema educativo colombiano, de manera concreta, demanda superar la tradición escolástica en la cual se encuentra inserto, que forma eruditos antes que ciudadanos capacitados para el ejercicio autónomo de la razón jurídica en la ponderación de la producción de normas con arreglo tanto al formalismo procedimental de su producción como a sus contenidos sustanciales dirigidos a la garantía de la fundamentalidad de los derechos humanos.

\section{REFERENCIAS BIBLIOGRÁFICAS}

Correas, O., (2002) Sociología del derecho y crítica jurídica. ISBN968-476-287-9. Editorial Fontamara.

Silva Garcia, G., (2009), Teoría Sociológica sobre la profesión jurídica y administración de justicia, Revista Prolegómenos, Derechos y Valores. 
Falcón, Fernando \& Tella. (2004), Tridimensionalismo y Derecho, Para una Teoria del Conocimiento. Universidad complutense de Madrid.

Arriola, J. F., (2010), Filosofía del derecho y derechos humanos

Rojas, V., (2008). Filosofía del Derecho de Jurgen Habermas, universidad nacional educación a distancia.

López, J.L. \& López, (2008), Razón comunicativa y legitimidad democrática.

López, J., (2004), Existencia, validez y nulidad de las normas jurídicas, universidad de Murcia. 